\title{
CONTRAPONDO ACORDOS ENTRE PESSOAS E PARQUES EM CONTEXTOS DO SUL
}

\section{RESUMO}

Joyce Gotlib ${ }^{1}$

Apresento, neste artigo, os resultados da pesquisa realizada no doutorado (2010-2016), acerca das estratégias engendradas por atores estatais, a fim de solucionar conflitos envolvendo projetos de desenvolvimento concorrentes: a criação de parques e a reparação histórica de comunidades negras por meio da titulação de seus territórios. Optei pelo estudo aprofundado de dois casos: o processo de titulação da comunidade quilombola de Ivaporunduva, localizada no Vale do Ribeira, e o da comunidade Bhangazi, situada na província de Kwazulu-Natal, África do Sul. Notei que, tanto no Brasil quanto na África do Sul, a conversão dos beneficiários em 'nativos ecológicos' (Ulloa, 2004) faz-se sob uma perspectiva de conservação pautada em um conceito de ambiente que mais se assemelha aos valores ocidentais, excluindo outras visões de mundo sobre o lugar demandado e suas agências.

Palavras-chave: Restituição de terras, Conservação ambiental, Populações tradicionais.

\section{CONFRONTING AGREEMENTS BETWEEN PEOPLE AND PARKS IN SOUTH CONTEXTS}

\begin{abstract}
In this article, we show the results of $\mathrm{PhD}$ research, elaborated between 2010 and 2016, about the strategies created by state actors to solve conflicts involving two competitor development projects: the creation of protected areas and the historical reparation of rural black communities throughout the entitlement of the their ancestral land. Methodologically, we adopted the case study thecnique, choosing two cases: the entitlement process of the Quilombola Community of Ivaporunduva, situated ate Vale do Ribeira, São Paulo, and, the Bhangazi community, located in the province of KwaZuluNatal, South Africa. Confirming our hypothesis, we try to demonstrate that, in Brazil and in South Africa, the conversion of beneficiaries into 'ecologic natives' (ULLOA, 2004) occur under a conservative perspective based on a concept of environment sympathetic to western values and excluding other cosmologies about the territory and their agencies.
\end{abstract}

Keywords: Land Restitution, Environmental Conservation, Traditional populations.

\section{INTRODUÇÃO}

No cenário contemporâneo dos países latino-americanos e africanos, tornaram-se costumeiros os conflitos envolvendo entidades ambientalistas e movimentos sociais de luta pela terra. A intrincada disputa entre esses sujeitos converte-se em dilemas, em certa medida insolúveis, para os atores estatais que lidam com as políticas públicas agrárias. Nesses casos, marcados pela sobreposição de demandas entre aqueles que reclamam o direito à terra e aqueles que ensejam um ambiente conservado, notei a hegemonia dos projetos de conservação, deixando à deriva comunidades tradicionais que deveriam ter tido reconhecidos os direitos ao território de seus ancestrais (Escobar, 1995).

\footnotetext{
1 Doutora em Ciências Sociais. Filiação: Professora de Sociologia do IFMT - campus Juína. E-mail: joyce.gotlib@jna.ifmt.edu.br
} 
Descrevo neste artigo, os resultados da pesquisa realizada no doutorado (2010-2016), a respeito das estratégias engendradas por atores estatais, a fim de solucionar conflitos envolvendo projetos de desenvolvimento concorrentes: a criação de parques e a reparação histórica de comunidades negras por meio da titulação de seus territórios. Optei elo estudo aprofundado de dois casos: o processo de titulação da comunidade quilombola de Ivaporunduva, localizada no Vale do Ribeira, titulada integralmente em 2010, e o da comunidade Bhangazi, situada na província de Kwazulu-Natal, África do Sul, titulada em 2003.

A análise que aqui apresento é resultante de um longo trabalho de pesquisa iniciado no mestrado, que se estendeu até os anos finais do doutorado, em $2016^{2}$. A investigação no contexto brasileiro se deu no período de 2010 a 2014, englobando visitas às cidades de São Paulo, sede dos órgãos estaduais de meio ambiente e de regularização fundiária; Eldorado Paulista, onde se localiza a comunidade Ivaporunduva e a sede do ISA (Instituto SocioAmbiental) no Vale do Ribeira e da EEACONE (Equipe de Articulação e Assessoria às comunidades negras do Vale do Ribeira), como também nos escritórios dos órgãos estaduais ambientais e de regularização fundiária, e a cidade de Brasília, sede nacional do INCRA e da Fundação Cultural Palmares, visitados em 2011. Na África do Sul, minhas viagens ocorreram entre os anos de 2009 e 2013, compondo, no total, três incursões. A primeira, durante o período do mestrado, se concentrou na província de KwaZulu-Natal, especificamente na área de atuação do Landless People's Movement (LPM) e da ONG AFRA (Association for Rural Advancement). Em 2012, durante meu doutorado, meu foco foram os funcionários partícipes do processo de restituição dos Bhangazi e a busca por documentos que se referissem ao caso. Assim, realizei visitas às cidades de Pietermaritztburgo, onde se situam os escritórios dos órgãos de regularização fundiária e ambiental; Mtubatuba, cidade vizinha ao parque Isimangaliso, no qual reside a maioria dos descendentes da comunidade Bhangazi; Santa Lucia, inserida no parque Isimangaliso ,e que concentra os maiores conflitos entre os beneficiários e os agentes públicos. Além desses locais, em 2013 retornei a esse país como palestrante na Universidade de Johhanesburgo, momento em que entrevistei o coordenador da ONG que gerencia o projeto de etnoturismo da comunidade Bhangazi e que dirigiu um documentário sobre este grupo, encerrando, assim, a pesquisa in loco. Priorizei o uso de métodos qualitativos, como a realização de entrevistas semiestruturadas e observação direta. Todavia, o estudo também me pautei em extensa pesquisa documental, a fim de alcançar os objetivos propostos de construir uma análise sócio-histórica dos processos investigados.

No Brasil, o processo de reconhecimento e titulação de terras tradicionalmente ocupadas por remanescentes de quilombos foi formalizado com a Constituição Brasileira de 1988. Na África do

\footnotetext{
${ }^{2}$ A autora é Doutora em Ciências Sociais pela UNICAMP (2010-2016), sob orientação da Prof. ${ }^{a}$ Dra. Evelina Dagnino; e, Mestre em Ciências Jurídicas e Sociais pela UFF (2008-2010), sob a orientação do Prof. Dr. Marcelo Carvalho Rosa.
} 
Sul, o projeto político de reparação histórica tornou-se parte da agenda do Estado, em 1994, quando o ANC (African National Congress), representado por Nelson Mandela, tornou-se governo. Esse projeto vincula-se à reparação da lei mais danosa do apartheid: Native Land Act, de 1913, que proibiu a população nativa de possuir, seja por meio de compra ou aluguel, terras fora dos limites das reservas. Dentre as várias formas para reparar as injustiças alavancadas por esse ato, a principal delas foi o Ato de Restituição de 1994, primeira legislação do governo do ANC, a qual prescrevia a restituição das terras à população forçosamente removida das terras de seus ancestrais.

As políticas de titulação das terras ocupadas por comunidades negras rurais, aqui e lá, enfrentam, desde sua fundação, disputas com as instituições de conservação ambiental, que veem a presença de populações humanas em áreas protegidas como uma ameaça a esses ecossistemas.

O processo de burocratização do conceito antropológico de 'populações tradicionais' é fruto de uma estratégia dos movimentos sociais, a fim de sanar conflitos entre a luta pela reforma agrária e conservação ambiental. Essa saída conceitual exprimiu, em larga medida, as demandas históricas daqueles que mantêm um vínculo tradicional com a terra que ocupam. Tal feito, que converteu posseiros em 'nativos ecológicos', colaborou, em alguma medida, para que esses sujeitos se tornassem visíveis ao Estado, já que, ao atribuir a esses grupos uma identidade ecológica - guardião da floresta -, torna-se possível a titulação de seus territórios. Como afirmou Almeida:

\begin{abstract}
Nas duas últimas décadas estamos assistindo em todo o País, e notadamente na Amazônia, ao advento de novos padrões de relação política no campo e na cidade. Os movimentos sociais no campo, que desde 1970 vem se consolidando fora dos marcos tradicionais do controle clientelístico e tendo nos Sindicatos de Trabalhadores e Trabalhadoras Rurais uma de suas expressões maiores, conhecem no momento atual, ou seja, desde 1988-89, certos desdobramentos, cujas formas de associação e luta escapam ao sentido estrito de uma entidade sindical, incorporando fatores étnicos, elementos de consciência ecológica e critérios de gênero e de autodefinição coletiva, que concorrem para relativizar as divisões político-administrativas e a maneira convencional de pautar e de encaminhar demandas aos poderes públicos (2004, página XX).
\end{abstract}

Assim, nos dois contextos estudados, o vínculo tradicional com o território foi essencial para que não só os Banghazi, como também a comunidade quilombola de Ivaporunduva se tornassem beneficiários públicos. No entanto, procurarei enfatizar que essa identidade não assegurou o livre manejo de suas terras. Tanto no Brasil quanto na África do Sul, é nítida a dificuldade dos técnicos de implementar os projetos arquitetados para essas comunidades e fazê-las, sobretudo, seguir as leis ambientais; além de imposição inerente ao programa de transformá-las em associações empreendedoras. A conversão em 'nativos ecológicos' (Ulloa, 2004) faz-se sob uma perspectiva de conservação pautada num conceito de ambiente que mais se assemelha aos valores modernos e ocidentais, excluindo outras visões de mundo sobre o lugar demandado e suas agências, fazendo naufragar, desde sua concepção, as propostas de empreendimento desenhadas pelos peritos. Tentarei demonstrar que o sucesso desses empreendimentos, quando ocorre, está relacionado ao perfil de suas 
lideranças e aos sentidos que empregam ao engajamento político no movimento social de luta pela terra.

\section{OS ACORDOS COM IVAPORUNDUVA}

Resolvendo as fronteiras com o parque

A comunidade de Ivaporunduva localiza-se na região paradisíaca do Vale do Ribeira, escondida às margens do Rio Ribeira do Iguape, no município de Eldorado Paulista, sudoeste de São Paulo. Em 1995, parte das terras da comunidade foi delimitada como área do Parque Estadual Intervales, impedindo a feitura de roças e a extração de palmito. O processo de reconhecimento, delimitação, regularização fundiária e titulação da comunidade de Ivaporunduva iniciou-se em fins dos anos oitenta, a partir do engajamento das suas lideranças pelo reconhecimento público de sua condição de remanescente de quilombo. As terras pleiteadas pela comunidade pertenciam à empresa Alagoinha empreendimentos e ao governo estadual paulista, sendo necessárias ações de regularização fundiária nos âmbitos estadual e federal. A primeira vitória desse coletivo foi a aceitação de seu pleito pelas autoridades estatais, em 1995, findando com a titulação integral da terra reivindicada, em 2010.

Em 1998, ano em que foi publicado o laudo antropológico da comunidade quilombola Ivaporunduva pelo FITESP (Fundação Instituto de Terras de São Paulo), o território do grupo encontrava-se sobreposto a duas unidades de proteção integral: o PEI (Parque Estadual Intervales) e o PEJ (Parque estadual do Jacupiranga). Nesse caso, apesar do reconhecimento de seu território frente ao Estado, as UCs (Unidades de Conservação) significavam um impedimento grave à manutenção daquelas comunidades, já que estas estavam submetidas às imposições das legislações ambientais vigentes.

A mudança nos limites das UCs foi prescrita por meio dos decretos 43.651 e 44.293, publicados em 1998 e 1999, respectivamente. Anos mais tarde, em 2008, foi publicada a Lei do Mosaico do Jacupiranga (publicada em 2008), que dispõe sobre a reclassificação das categorias das UCs do PEJ, visando o reconhecimento das terras ocupadas por remanescentes das comunidades de quilombos e a permissão do manejo territorial sustentável, nos termos do artigo 68, do ato das disposições constitucionais transitórias da Constituição Federal (Ver quadro 1).

Quadro 1: Atos legislativos- Regularização fundiária de Ivaporunduva

\begin{tabular}{|c|c|c|}
\hline Ano & Atos legislativos & \multicolumn{1}{c|}{ Conteúdo } \\
\hline & $\begin{array}{c}\text { Projeto de Lei de Beatriz Pardi, do } \\
\text { PT(Partido dos Trabalhadores) }\end{array}$ & $\begin{array}{l}\text { Proposta de exclusão das áreas ocupadas por remanescentes } \\
\text { das comunidades de quilombos PEJ e PEI }\end{array}$ \\
\hline
\end{tabular}




\begin{tabular}{|c|c|l|}
1998 & Decreto 43.651 & $\begin{array}{l}\text { Prescreveu que as terras ocupadas por remanescentes de } \\
\text { quilombos não farão mais parte da UC Serra do Mar. }\end{array}$ \\
\hline 1999 & Decreto 44.293 & $\begin{array}{l}\text { Decretou que as terras reconhecidas como de propriedade } \\
\text { definitiva dos remanescentes das comunidades de quilombos } \\
\text { não faziam mais parte do PEI }\end{array}$ \\
\hline 1999 & $\begin{array}{c}\text { Projeto de lei de Renato Simões, do } \\
\text { PT }\end{array}$ & $\begin{array}{l}\text { Versava sobre a alteração dos limites dos parques estaduais } \\
\text { PEI e PEJ, visando o reconhecimento da aquisição do domínio } \\
\text { das terras ocupadas por remanescentes das comunidades de } \\
\text { quilombos, nos termos do artigo 68 do ato das disposições } \\
\text { constitucionais transitórias da CF de 1988. }\end{array}$ \\
\hline 2001 & Lei 10.850 & $\begin{array}{l}\text { Aprovação da PL de Renato Simões na íntegra. } \\
2008\end{array}$ \\
\hline
\end{tabular}

Quando questionei questionar a analista agrária do FITESP, a qual, na época, participou do processo de regularização fundiária de Ivaporunduva, como se deu a mudança nos limites dos parques, a servidora justificou:

\begin{abstract}
No início dos trabalhos havia um grupo gestor que se reunia, mas o controle sobre os técnicos era bem menor que hoje em dia. Se havia uma área de parque sobreposta à reivindicação dos quilombolas, havia um pouco de liberdade para fazer a demarcação das terras dos remanescentes. Hoje em dia, esta demarcação tornou-se bem mais conflituosa (Entrevista com analista em assuntos fundiários do FITESP, março de 2011).
\end{abstract}

A liberdade de atuação dos servidores pode ser atribuída a diversos fatores: ao caráter inédito das iniciativas de regularização fundiária, endereçadas aos quilombolas no Estado, à falta de normas relativas à sua execução, à vontade política do governador Covas em efetivar esses direitos e, por último, aos sujeitos que ocupavam cargos de alto escalão na Secretaria de Meio Ambiente e na Secretaria da Justiça.

Mesmo com a desafetação, a Fundação Florestal continuou negando direitos aos quilombolas, alijando-os das condições inerentes à permanência daquelas comunidades em seus territórios. Os dados que coletei nas entrevistas realizadas com técnicos do FITESP apontam para a existência de impasses burocráticos e ideológicos em executar as ações propostas nos projetos e nas diretrizes estabelecidas pelo Grupo gestor de Quilombos, inclusive a de licenciamento das roças

As parcerias com o ISA: a capacitação para o desenvolvimento sustentável

Apresento agora, como foi desenhado o projeto de capacitação em desenvolvimento sustentável da comunidade de Ivaporunduva, incluindo a escolha de seu carro chefe: a produção de banana orgânica.

O ISA, entidade reconhecida pela expertise no campo socioambiental, foi selecionado para desenvolver o PGAPDE (Projeto Gestão Ambiental Participativa e Desenvolvimento Econômico) da Comunidade Ivaporunduva, custeado pelo MMA (Ministério de Meio Ambiente). O Projeto em 
questão estava amparado na premissa de que as comunidades quilombolas do VR não possuíam, até aquele momento, alternativas capazes de assegurar o desenvolvimento socioeconômico de suas populações, o que colocaria em risco, de acordo com Pedroso (2008, p. 35), "a permanência no campo e equilíbrio ambiental da maior área contínua de Mata Atlântica do país".

Com relação às propostas documentadas no Termo de Cooperação Técnica, firmado entre as duas entidades, observei que o objetivo do acordo foi transferir a expertise dos técnicos contratados pela entidade para os coordenadores locais dos projetos a serem desenvolvidos pela comunidade. As atividades de capacitação técnica incluíram: plano de gestão ecológica e econômica do território quilombola, o enriquecimento de áreas degradadas com o palmiteiro juçara (Euterpe edulis), englobando, no total, duzentos hectares de terra; a agregação de valor aos produtos das atividades já desenvolvidas na comunidade (cultura da banana, certificação orgânica dos produtos agrícolas, utilização da fibra da bananeira na confecção do artesanato); a melhoria do ambiente do núcleo urbano da comunidade com investimentos em infraestrutura por meio da compra de um caminhão de médio porte para o transporte e comercialização da banana ${ }^{3}$, trinta teares para confecção do artesanato ${ }^{4}$, construção de um galpão e construção da casa de artesanato $^{5}$ e, por último, a confecção da identidade visual da Associação ${ }^{6}$ de Ivaporunduva. De acordo com a ficha do PGAPDE, o trabalho de capacitação foi feito no formato de seminários com a comunidade sobre técnicas de agricultura orgânica, oficinas, feiras de artesanato, atividades de educação ambiental e produção de apostilas (Ministério de Meio Ambiente, 2003).

As parcerias com o ITESP: a capacitação para o turismo

Dentre os projetos desenvolvidos pelo FITESP em Ivaporunduva, destaco aqui o curso de capacitação para monitores ambientais, realizado em 2001. Ao final desse projeto, quatro monitores ambientais estavam formados e aptos para atuar dentro e fora da comunidade. O foco do curso era a Espeleologia, já que a região concentra um grande número de cavernas. A Caverna do Diabo, um dos atrativos turísticos da cidade, localiza-se a pouco mais de cinco quilômetros da comunidade, oferecendo oportunidade de trabalho, em curto prazo, para os moradores de Ivaporunduva. Nesse

\footnotetext{
${ }^{3}$ De acordo com Melo (2008), o Projeto de comercialização da banana orgânica, desenvolvido na comunidade pelo ISA, teve a participação do FITESP de Eldorado, que facilitou a emissão da Declaração de Aptidão ao Pronaf, o que permitiu a formalização do projeto junto à CONAB (Companhia Nacional de Abastecimento). Concomitante a isso, o Projeto Artesanato recebeu a ajuda de Marta Negrão, do FITESP, como apoio técnico.

${ }^{4}$ A atividade artesanal com a palha de bananeira, da forma como é feita atualmente, se iniciou em 1997, após um curso de capacitação dado pelos pesquisadores da ESALQ para os moradores do quilombo. Em 2001, 10 moradores desenvolviam produtos a partir da fibra da bananeira como atividade comercial (Pedroso, 2008).

${ }^{5}$ A Casa do artesanato foi construída no primeiro semestre de 2002.

${ }^{6} \mathrm{O}$ termo Associação é utilizado neste artigo com letra maiúscula, pois está se referindo a entidade jurídica formada pelos representantes da comunidade quilombola de Ivaporunduva.
} 
caso, a capacitação visava profissionalizar indivíduos da comunidade, a fim de aprimorar as atividades de turismo que a comunidade oferecia desde 1997 para instituições educacionais.

Além do curso, a entidade estatal iniciou a construção de um hotel em Ivaporunduva, para receber excursões de estudantes interessados na vida comunitária dos quilombos, projeto financiado pelo Programa ‘Equipamentos Comunitários'.

Só pelo programa Equipamentos Comunitários, foram investidos R\$ 203 mil no fornecimento de material para construção de seis agroindústrias e de dois centros comunitários em assentamentos. Inédito em áreas quilombolas, um centro de recepção de visitantes também vai ser construído em Ivaporunduva, município de Eldorado (Fatos da Terra, 2002, p. 14).

De acordo com o periódico publicado pelo FITESP, os beneficiários do projeto poderiam decidir qual equipamento se adequaria melhor às necessidades da comunidade. Diferente dos demais grupos contemplados, que optaram em gastar o recurso em habitação e equipamentos agrícolas, os representantes de Ivaporunduva decidiram aprimorar os serviços de hospedagem oferecidos aos turistas, que antes eram hospedados na casa dos moradores. Durante uma conversa com uma das interlocutoras de minha pesquisa, que trabalha no FITESP, a servidoradestacou a capacidade organizacional da comunidade:

Os moradores de Ivaporunduva já eram cabeça feita, já sabiam de seus direitos, já haviam se organizado anteriormente. Anteriormente, era preciso dizer, alertá-los sobre seus direitos. Agora, eles vêm dizer o que querem para nós (Entrevista realizada com Ignês Maricondi, março de 2011).

Os engajamentos da Associação

O quilombo de Ivaporunduva destaca-se dos demais quilombos pelo grau de organização e autonomia relativa frente às entidades estatais e organizações não governamentais.

Esse quilombo é reconhecido tanto no âmbito local, quanto nos âmbitos nacionais e internacionais. Isso pode ser observado não só na literatura sobre as comunidades quilombolas do Vale do Ribeira, mas também no discurso dos políticos e servidores públicos inseridos nessa contenda. As lideranças são vistas como porta-vozes dos quilombolas e, regularmente, são convidadas para eventos nacionais e internacionais, que abordam a temática negra e quilombola.

Durante a investigação, pude perceber que a Associação vinha se empenhando para participar dos editais de fomento, disponibilizados pelo governo federal, por meio do Ministério de Desenvolvimento Agrário e do de Meio Ambiente. Anteriormente, os recursos federais chegavam à comunidade por meio das ONGs, que mediavam a relação entre as agências financiadoras e a comunidade. De acordo com o presidente da Associação (em exercício em 2013), os líderes daquela comunidade, naquela ocasião mais jovens do que aqueles que ocuparam esses cargos há dez anos, 
têm optado por driblar as entidades intermediárias, passando a elaborar seus próprios projetos, candidatando-se nos editais que encaixam as propostas ensejadas pela Associação.

Assim, percebo que a estratégia recente de elaboração de projetos de fomento e desenvolvimento reposicionou Ivaporunduva na arena de disputas local, tornando-a concorrente aos recursos disputados pelas ONGs. Segundo o presidente do grupo, “A Associação aprendeu o caminho das pedras e vem funcionando como sua própria ONG”. Nesse caso, além de beneficiária, cada vez mais, os representantes de Ivaporunduva vêm buscando firmar parcerias e projetos, posicionando-se como uma articuladora e mediadora. Ao observar o modus operandi das atividades etnoturísticas desenvolvidas durante a realização da pesquisa em Ivaporunduva, notei que a Associação se tornou o principal mediador da comunidade, ganhando autonomia, em certa medida, do ISA e do FITESP.

Em 2009, o ISA inaugurou, em conjunto com nove comunidades quilombolas do Vale do Ribeira, o 'Circuito Quilombola', que tem como proposta o turismo de base comunitária. O intuito era incentivar a atividade turística nos quilombos, colaborando para o aumento da renda das famílias quilombolas. Apesar de Ivaporunduva fazer parte do circuito, a maior parte das atividades turísticas desenvolvidas na comunidade ocorre em parceria com o SESC (Serviço Social de Comérico) e a CONAB (Companhia Nacional de Abastecimento), que articulam a ida de grupo de estudantes para o quilombo.

Com relação à autonomia relativa frente ao FITESP, o que surpreende é a articulação interna dos membros para profissionalizar os mais novos, investindo na formação de um corpo de profissionais especialistas em turismo, dispensando a entrada de agentes externos.

Durante os quinze anos de investimentos internos e externos no turismo cultural, o Quilombo Ivaporunduva organizou seu território, ergueu equipamentos para a recepção dos turistas e elaborou passeios, rotas e trilhas com a intenção de destacar a cultura e história da comunidade, procurando driblar os impedimentos agroextrativistas impostos pela lei ambiental.

\section{OS ACORDOS DE RESTITUIÇÃO COM OS BHANGAZI}

No outro lado do atlântico, a terra reivindicada pelos Bhangazi recai também sobre um cenário paradisíaco: o norte da província de Kwazulu-Natal, hoje denominado Parque Úmido Isimangaliso, que congrega florestas úmidas, lagos e praias exuberantes. No sudeste do Lago Santa Lucia, próximo ao lago Bhangazi, na região de Nkokhweni, viveram cerca de 500 famílias do clã Mbuyazi por, no mínimo, seis gerações. Em 1956, a área foi declarada um Black spot e seus moradores receberam a primeira notícia de remoção. A área, delimitada como Parque Santa Lucia, seria utilizada para a plantação de pinheiros e para uso turístico da população branca. A reivindicação desse grupo tornouse pública por meio da batalha entre movimentos em defesa da conservação ambiental e interessados 
na exploração mineral de titânio nas dunas que separam o Lago St Lucia do mar. O Relatório de Impacto Ambiental (EIA/RIMA), publicado em 1993, produzido a partir desse embate, e os comentários subsequentes expuseram a história de ocupação e remoção dos Bhangazi, incluindo suas demandas, obtidas durante as investigações dos especialistas contratados para a construção do documento (CSIR, 1993). Em 1995, a Comissão de Restituição de Terras de KwaZulu-Natal aceitou o pedido protocolado no órgão e deu início ao processo de restituição. Em setembro de 1999, foram assinados os acordos entre os Bhangazi, a Autoridade $^{7}$ do parque e a Comissão de Terras.

Após o acordo de settlement, assinado entre os Bhangazi e o Departamento Nacional de Assuntos Fundiários, iniciou-se o processo denominado post setlement support, fase em que a Trust se converte em beneficiária de projetos, visando o desenvolvimento econômico da comunidade. Segundo o acordo de settlement, assinado em 1999, a comunidade teria direito à exploração hoteleira da terra titulada, à construção de um centro cultural para a preservação das memórias da comunidade e de seu patrimônio cultural, ao auxílio para a produção e escoamento do artesanato produzido pelas famílias (leia-se mulheres), e à venda nas lojas do parque. A execução desses projetos envolveu também a entrada de instituições parceiras, como empresas privadas e ONGs.

O acordo com o Departamento Nacional de Terras.

Em setembro de 1999, a Trust Bhangazi assinou o acordo formal de settlement com o Departamento Nacional de Terras. O documento firmado com os claimants foi feito nos moldes de um título formal de propriedade, determinando um valor total pela terra reclamada. A partir desse valor, dividiu-se o montante entre as famílias beneficiárias. $\mathrm{O}$ valor total acertado foi de $\mathrm{R}$ 16.680.000,00 (dezesseis milhões, seiscentos e oitenta mil Rands) ${ }^{8}$, dividido por 556 (quinhentos e cinquenta e seis) famílias, ou seja, aproximadamente R 30.000 (trinta mil Rands) ${ }^{9}$ por família ${ }^{10}$.

No caso Bhangazi, o tipo de settlement acordado no memorando englobava: a compensação financeira, a participação da Trust no desenvolvimento da região sem a restauração do título formal da terra e o pequeno lote titulado em nome da associação denominado Sítio de Herança.

Os acordos com o órgão ambiental.

\footnotetext{
${ }^{7}$ O vocábulo Autoridade utilizado ao longo do artigo, quando em letra maiúscula, refere-se a entidade estatal criada para gerenciar o Grande Parque Isimangaliso, respeitando o termo em inglês Isimangaliso Authority. Até o ano de 2013, esta estava sob o comando de Andrew Zaloumis.

${ }^{8}$ Atualmente, o valor correspondente em dólares é aproximadamente \$1.128.000,00 (um milhão cento e vinte e oito mil).

${ }^{9}$ Atualmente, o valor corresponde, em dólares, a aproximadamente $\$ 2.000,00$ (dois mil).

${ }^{10}$ John conta que se encontrava com os claimants pelo menos uma vez ao mês para tentar chegar a um acordo quanto ao settlement. Segundo ele, havia muita discordância entre os claimants. Phineas Mbuyazi era o único que defendia o retorno para a terra ancestral. O resto dos trustees queria a compensação financeira e uma parcela dos recursos recebidos pelo parque.
} 
O segundo acordo firmado com a Trust foi assinado entre os reclamantes e a entidade ambiental de KwaZulu-Natal. Conforme o documento, a Trust Bhangazi seria a beneficiária principal da arrecadação monetária proveniente da tarifa de entrada paga pelos turistas. O dinheiro seria distribuído da seguinte forma: setenta por cento para a Trust, vinte por cento para a Autoridade Tribal Mpokonyoni e dez por cento para a entidade ambiental.

Com relação aos direitos de uso e ocupação, de acordo com o memorando, a entidade ambiental seria responsável por demarcar um pequeno lote de terra para a construção de um sítio histórico em homenagem aos ancestrais dos Mbuyazi e a conservação de outros locais dentro do parque, como aqueles onde se situam outros túmulos de familiares falecidos dos Bhangazi, que encontram-se localizados fora dos limites da área demarcada como Sítio de Herança.

Segundo o acordo, o parque só permitiria a entrada dos antigos residentes em horas previamente agendadas, e o manejo de ervas tradicionais só poderia ocorrer em determinadas épocas do ano, mediante prévia autorização da Autoridade.

A insistência em um plano de conservação pautado na natureza intocada pode estar relacionada à falta de rotatividade dos funcionários da entidade estatal ambiental que manteve seu staff praticamente intacto, mesmo após a mudança de governo, em 1994. De acordo com Walker, a sunset clause $^{11}$ tornou-se um obstáculo de peso na execução da nova política de reparação das injustiças encabeçadas pelo ANC. Mesmo que a entidade estatal fosse conhecida como uma instituição menos ortodoxa e em defesa de projetos mais democráticos que aqueles zelados pelo Partido Nacional (no poder entre 1948 e 1990), seu modelo de conservacionismo era incompatível com a política de restituição de terras, tão cara ao ANC.

O acordo com a Autoridade Isimangaliso

Verifiquei a partir de 1998, uma mudança paulatina no regramento e manejo dos parques nacionais sul-africanos, confirmada a partir da promulgação de dois atos: o Ato de Gerenciamento Ambiental (National Environmental Management Act) e o Ato de Patrimônios Mundiais (World Heritage Act). O primeiro ato citado tinha como premissa o empoderamento local e a coparticipação da população local nos projetos de desenvolvimento e turismo levados a cabo em áreas protegidas, e a segunda legislação citada acima incorporou os direitos culturais, financeiros e políticos dos beneficiários das políticas de restituição.

Embasado nessas medidas e no reconhecimento mundial da área do parque como patrimônio da humanidade, cria-se o GSLWP (Greater St Lucia Wetland Park), renomeado Parque Úmido

\footnotetext{
${ }^{11} \mathrm{O}$ termo sunset clause refere-se ao compromisso firmado entre o ANC e o partido Nacional que governou a África do Sul até 1993, para que o novo governo não substituísse de forma drástica os cargos no governo. O acordo era que isso fosse feito de forma gradual, mantendo parte do antigo governo no poder por mais cinco anos.
} 
Isimangaliso $^{12}$ (Isimangaliso Wetland Park). Em 2000, foi criado um aparato burocrático denominado Autoridade Isimangaliso, para assumir a gestão desse complexo de áreas protegidas, incluindo, nessa contenda, a responsabilização sobre a implementação dos acordos firmados entre o Estado sul-africano (por meio de seu órgão de terras) e outras claims de restituição, como a do Bhangazi.

Em síntese, este novo órgão refez o antigo acordo existente entre os Bhangazi e a entidade ambiental provincial. Novas cláusulas foram adicionadas ao antigo documento, assinado em 1997, dentre elas: a mudança geográfica do sítio histórico dos Bhangazi e a ampliação da área dedicada aos ancestrais da comunidade; a contratação de uma empresa privada especializada para a construção do museu e do lodge no sítio histórico destinado à Trust; a ênfase na responsabilidade da Autoridade do parque Isimangaliso em prover oportunidades de emprego e educação para os claimants; $e$ o reconhecimento da Trust pela Autoridade, como um parceiro obrigatório, no que tange às atividades turísticas desenvolvidas no parque.

Segundo as normativas acordadas, o hotel, assim como o museu, seria cogerenciado pela Trust e pela Autoridade do parque, por meio de uma parceria entre as duas entidades. Além desses novos compromissos, conforme o conteúdo da nova legislação, a entidade gestora da UC deveria prover aos grupos afetados pela criação do parque, incluindo os Bhangazi, oportunidades de emprego e contribuir para a melhoria das condições de vida da população local.

O empreendimento hoteleiro

A ONG selecionada para dar suporte aos Bhangazi, no processo de decisão do projeto de desenvolvimento a ser desenvolvido em seu sítio histórico, foi a ASF (Africa Safari Foundation). A entidade não era novata: seu diretor, Peter John, já havia trabalhado com os Bhangazi ao lado de Eddie Kock, no início dos anos 2000, na produção de um filme sobre os dilemas do grupo, intitulado 'Buffalo Thorn'.

De acordo com entrevista realizada com Peter, em 2013, o empreendimento hoteleiro no sítio histórico dos Bhangazi teria aproximadamente vinte e cinco apartamentos, e os beneficiários teriam também direito de realizar atividades turísticas no parque, como caminhadas monitoradas com os turistas e passeios de barco no lago, nas quais seriam dadas informações sobre a história do grupo que viveu naquelas terras e sua relação histórica e cultural com a região oriental do lago St Lucia, evidenciando suas tradições. John sugeriu ao grupo convidar uma terceira entidade parceira para a reforma do Lodge, especializada em projetos de desenvolvimento sustentáveis na área de agricultura

\footnotetext{
${ }^{12} \mathrm{O}$ complexo mudou de nome, acompanhando as mudanças linguísticas levadas a cabo, com o fim do apartheid, sendo renomeado Isimangaliso Wetland Park. De acordo com o presidente da Trust Bhangazi, o novo nome foi dado por Mandela. Em 1999, ele teria sobrevoado a região e afirmado que esse lugar era "um milagre” (Isimangaliso em IsiZulu).
} 
e turismo para grupos beneficiários de políticas estatais. A empresa Vumelanga concordou em trabalhar para os Bhangazi, mas ainda dependia de uma resposta do Isimangaliso. O processo de modernização do lodge encontrava-se embargado, aguardando a publicação de um estudo de impacto ambiental a respeito dos impactos do hotel no ecossistema do parque. Segundo Peter:

Existe um embargo do Isimangaliso para a realização do empreendimento e, devido ao seu poder político imenso, nada está sendo feito. O processo só caminha quando há visita de algum político ou quando o governo nacional pressiona o órgão. Não existe vontade em caminhar com a questão (Entrevista com Peter John, Johhanesburgo, maio de 2013).

\section{CONSIDERAÇÕES FINAIS: ACORDOS EM PERSPECTIVA}

Durante a investigação, percebi inúmeras semelhanças envolvendo os acordos tecidos entre as entidades estatais e ONGs, e as comunidades Ivaporunduva e Bhangazi, com destaque para: as restrições de uso agrícola do território, a inserção das lideranças locais na gestão dos parques e a elaboração de propostas de empreendimentos turísticos aos beneficiários dessas políticas públicas, além da difusão e imposição do conceito de 'desenvolvimento sustentável'.

Os acordos entre Ivaporunduva e o ISA e aqueles firmados entre os Bhangazi e as entidades ambientais demonstram a hegemonia das ideias conservacionistas acerca do ambiente, podendo ser uma chave para compreender o fracasso desses projetos. Esses estão pautados em visões de mundo sobre a natureza e o funcionamento do meio, que diferem consideravelmente das conceituações nativas acerca do funcionamento dos seres que englobam sua realidade vivida. Como exemplo, citarei aqui a proibição da feitura de roças em sistemas de coivara e os cursos de capacitação para a produção de banana orgânica em Ivaporunduva. As ideias de pureza e perigo embutidas nessas propostas referem-se a sistemas ontológicos eurocêntricos, divergentes das noções de pureza e perigo difundidas entre os quilombolas do Vale do Ribeira. No caso Bhangazi, a ruína dos projetos de desenvolvimento desenhados pelos ambientalistas está indubitavelmente relacionada à divergência das cosmologias nativas e ocidentais acerca do ambiente e sua conservação. Enquanto, para os Bhangazi, o vínculo frequente entre seus líderes clânicos e os animais de seu território são essenciais para sua sobrevivência e os parentes $\operatorname{mortos}^{13}$, para os ambientalistas, a permanência humana ao redor do lago causaria a destruição do ecossistema. Nesse caso, as matrizes ontológicas associadas às restrições de uso e a imposição de períodos determinados para a caça distanciam-se das concepções nativas acerca dos períodos de caça e sua periodicidade, apenas para citar um exemplo. Além disso, notei que, mesmo tendo as terras tituladas, a maioria das restrições de uso permanece inalterada. Ou

\footnotetext{
13، The lake dweller - the hippopotamus of Lake Bhangazi- has a special relationship with our family. It is one of the secrets of th Mbuyazi family. We communicated with the hippo regularly. But now that I am no longer at Bhangazi, that it is difficult. This is now the second year that I have not been able to go to the lake and talk to them" (Entrevista feita por Walker em 2003 apud Walker, 2008)).
} 
seja, a titularidade da terra não significou a liberdade de usufruto e das decisões concernentes aos seus usos. De acordo com Iáskara Saldanha, do NUPAUB (Núcleo de Pesquisas sobre Áreas Úmidas Brasileiras), entrevistado por Maurício Filho, em 2005:

$\mathrm{O}$ veto à caracterização oficial das populações tradicionais na lei que instituiu o Snuc ${ }^{14}$ no Brasil, ficou demonstrado que as iniciativas públicas são ainda muito incipientes no que se refere a dar garantias a essas comunidades, especialmente tratando-se de não-indígenas.

Mais uma vez, a hegemonia dos modos de pensar da ciência ocidental incide sobre as populações originárias, excluindo-as da modernidade e, consequentemente, da participação na definição das matrizes discursivas sobre natureza e cultura (Latour, 2004).

Contrapondo os dois casos, constatei que o empoderamento político de Ivaporunduva e, também, o reconhecimento dado pelo Estado às populações tradicionais colaboraram para a permanência da comunidade no território que ocupam, diferentemente do caso Bhangazi. O engajamento de seus líderes não foi suficiente para derrubar as restrições impostas pelos ambientalistas, que, historicamente, mantém uma relação próxima com o Estado, datada do início do período colonial.

Percebi ainda, que o relativo sucesso do empreendimento turístico em Ivaporunduva pode estar associado ao engajamento político de suas lideranças, no nível escolar e técnico destes sujeitos e na faixa etária dos militantes quilombolas. A Associação do quilombo, no momento de realização da pesquisa, era formada por lideranças jovens, a maioria delas com ensino médio completo ou com diploma de técnico ou superior, motivadas pelo desenvolvimento econômico de sua comunidade, e também, engajadas em frear a migração de seus membros mais jovens para a cidade.

No caso sul-africano, os trustees representantes dos Bhangazi têm faixa etária entre 40 e 60 anos e mantêm uma desconfiança entre si, devido, em larga medida, ao rompimento dos laços das famílias que compõem a claim Bhangazi (haja vista o longo tempo passado da remoção). Com relação à faixa de idade, ROSA (2004), em suas pesquisas sobre o movimento sem-terra sul-africano LPM, vem chamando atenção para as diferenças de idade entre os militantes sem-terra brasileiros e sulafricanos, diferenças essas explicadas a partir dos sentidos imputados ao engajamento político pelos sem-terra em cada um desses contextos.

Outro ponto de destaque é o contraste entre os empreendimentos hoteleiros em vigor nas comunidades tituladas. Em Ivaporunduva, as dificuldades vêm sendo superadas pela organização e união de seus líderes, pela antiguidade da comunidade e pelo alinhamento político de suas lideranças. Observei que a Associação vem desenvolvendo táticas para criar autonomia tanto da ONG como do Estado. No caso Bhangazi, as barreiras impostas pelos ambientalistas, dentro e fora do Estado,

\footnotetext{
${ }^{14}$ Sistema Nacional de Unidades de Conservação Ambiental, criado pela Lei Federal no 9.985, de 18 de julho de 2000 (nota da autora).
} 
dificultam a autonomia da trust. Os impedimentos narrados por Peter John parecem indicar que não há uma vontade política da Autoridade do parque em romper os laços de dependência construídos com os beneficiários públicos, demonstrando que essas políticas públicas funcionam, em sua maioria, para manter o poder do estado sobre os indivíduos (Ferguson, 1990). Nas reuniões de que participei entre trustees e representantes do governo, ficou claro que parte das estratégias da gestão do Isimangaliso era fomentar a competitividade entre as lideranças de cada trust.

Portanto, traçando um paralelo com o pensamento de Mignolo (2012) e Quijano (2000), a respeito da colonialidade do poder, verifiquei que o tipo de 'desenvolvimento' previsto nesses acordos ancora-se numa visão colonial sobre meio ambiente e conservação. No entanto cabe questionar se nesses agréments, firmados entre as entidades estatais, as ONGs e as comunidades, tanto no contexto brasileiro como no sul-africano, encontram-se expressões locais e particulares destes coletivos, ou seja, narrativas, conceitos e saberes, resultantes da luta das comunidades Ivaporunduva e Bhangazi frente ao desenvolvimento que se instaurou a partir dos anos sessenta sobre seus territórios, como seria o caso dos projetos de etnoturismo e os etnomapas produzidos em Ivaporunduva. Esta é uma questão para trabalhos futuros.

\section{REFERÊNCIAS}

ÁFRICA DO SUL. Department of Land Affairs. Deed of Settlement-Bhangazi Land Claim, 1999.

ALMEIDA, Alfredo Wagner Berno de. Terras tradicionalmente ocupadas. Processos de territorialização e movimentos sociais. Revista brasileira de estudos urbanos e regionais, v. 6, n. 1, 2004.

ARTURO, Escobar. Encountering development: the making and unmaking of the third world. Princeton University Press. Princeton. New Jersey, 1995.

CSIR ENVIRONMENTAL SERVICES. Environmental Impact Assesment, eastern shores of Lake St Lucia (KingsdTujan lease area), 3. Environmertal Impact Report. Pretoria: Environmental Services, 1993.

DIEGUES, Antonio Carlos Sant'Ana. O mito moderno da natureza intocada. São Paulo: Hucitec, 1996.

FERGUSON, James. The anti-politics machine. IN: SHARMA, Aradhana e Gupta, Akhil (Org) The anthropology of the state: a reader, Blackwell publishing, 1990, p. 270-86.

FILHO, Maurício Monteiro. Modernidade não dá espaço a saberes tradicionais. Repórter Brasil. Disponível em http://reporterbrasil.org.br/2005/04/modernidade-nao-da-espaco-a-saberestradicionais $/>.1^{\circ}$ de abril de 2005

FUNDAÇÃO INSTITUTO DE TERRAS DO ESTADO DE SÃO PAULO. Fatos da Terra, no 10. 2002.

ISIMANGALISO AUTHORITY PARK. Memoramdum of Agreement between Bhangazi Trust and Isimangaliso Authority Park, 2005.

KWAZULU-NATAL. Memorandum of Understanding between Bhangazi Trust and Kwazulu-Natal Nature Conservation Board, 1999. 
LATOUR, Bruno. Jamais fomos modernos. Editora 34, 1994.

MELO, Paula Balduino de. Práticas produtivas e políticas públicas: uma experiência quilombola no Vale do Ribeira/SP. 2010. 187 f., il. Dissertação (Mestrado em Antropologia Social) - Universidade de Brasília, Brasília, 2010.

MIGNOLO, Walter. Local histories/global designs: Coloniality, subaltern knowledges, and border thinking. Princeton University Press, 2012.

MINISTÉRIO DE MEIO AMBIENTE. Ficha do projeto Gestão Ambiental Participativa e Desenvolvimento Econômico do Quilombo de Ivaporunduva. Disponível em http://www.mma.gov.br/estruturas/pda/_arquivos/prj_1010_fch.pdf

PEDROSO, Fábio Graf. As experiências de desenvolvimento sustentável do quilombo de Ivaporunduva: um estudo de caso na perspectiva da agroecologia. 2008.

QUIJANO, Anibal. Coloniality of power and Eurocentrism in Latin America. International Sociology, v. 15, n. 2, p. 215-232, 2000.

ROSA, Marcelo Carvalho. Landless experiences: youth and social movements in Brazil and South Africa. Disponível em http://ceas.iscte.pt/ethnografeast/papers/marcelo_rosa.pdf

ULLOA, Astrid. La construcción del nativo ecológico: complejidades, paradojas y dilemas de la relación entre los movimientos indígenas y el ambientalismo en Colombia. Instituto Colombiano de Antropología e Historia (ICANH), 2004.

WALKER, Cherryl. (2008). Landmarked: land claims and land restitution in South Africa. Jacana Media. 